Severin Beatrice ${ }^{1}$, Damaschin Floarea ${ }^{1}$, Ion Ileana ${ }^{2}$, Adumitresi Cecilia ${ }^{2}$, Oancea Victoria ${ }^{3}$, Broasca V. Mocanu Elena ${ }^{4}$, Chirila S. ${ }^{4}$

\title{
The Prevalence of Chronic Diseases by Exposure to Nitrates from Environmental Factors
}

\author{
${ }^{1}$ Hygiene Discipline, Department I, Faculty of Medicine, "Ovidius" University, Constanta \\ ${ }^{2}$ Discipline of Physiology, Department I, Faculty of Medicine, "Ovidius" University, Constanta \\ ${ }^{3}$ Medical Office, Constanta County \\ ${ }^{4}$ Discipline of Public Health and Management, Department I, Faculty of Medicine, “Ovidius" University, \\ Constanta
}

\begin{abstract}
The study aims to analyze the health effects caused by chronic exposure to elevated levels of nitrates in the water in order to improve prevention of some diseases. We analyze water quality from two villages of Constanta County in the period 2006-2012 and we take data about chronic diseases from family doctors of these localities. Analyzes on water samples were made in the laboratory of the Public Health Department. We found a significant increase of prevalence for chronic diseases in locality exposed to nitrates.
\end{abstract}

Keywords: water, nitrates, health

\section{Beatrice Severin MD}

Faculty of Medicine, „Ovidius”University Constanta

1 University Alley, 900470 Constanta

Tel. 0745887518

E-mail: biaseverin2005@yahoo.com

\section{Introduction}

Water is an essential factor in ensuring and maintaining quality of life and public health. Because of multiple possibilities of disease by water consumption, it must meet a number of quality conditions to be considered potable: organoleptic, physical, chemical, microbiological.

Sanitary controls on drinking water quality revealed in many parts of the world a content of nitrates exceeding the maximum permitted by the World Health Organization.

For this reason serious manifestations are seen in artificially fed infants that make acute and often deadly so-called "blue baby disease" or methemoglobinemia.

In the same environmental conditions (polluted water) adults make chronic poisoning, which unfortunately are not notified in time by the patient or end up being attributed to other causes, and therefore are treated incorrectly. 
Given these data, through this study we wanted to analyze some aspects of the health situation in relation to water quality in Constanta County.

\section{Material and methods}

To analyze water quality in Constanta County and identify areas that have exceeded the maximum permitted levels for nitrate, we performed chemical analyzes on water samples collected from Constanta County, both rural and urban areas. After that we identified localities with normal levels of nitrates in water supplied by centralized system and localities which frequently recorded high concentrations of nitrates. To continue the study, we selected one village from each category. Analyzes on water samples were made in the laboratory of the Public Health Department in the period 2006-2012.

For the analysis of chronic diseases we used data taken from chronic disease registry of family doctors, from patient record files and from the records made for reporting to Constanta Health Insurance in the period 2006-2011.

\section{Results}

For village with chronic exposure to nitrates (Corbu - test locality) we collected 51 water samples from centralized system of the village. 37 of samples, representing $72.54 \%$ of total not complied with the legal standards for nitrates. Average of nitrates often exceeds the double of normal values (Figure 1). Maximum value $(458 \mathrm{mg} / 1)$ is obtained in 2008 and is nine times higher than sanitary rules!

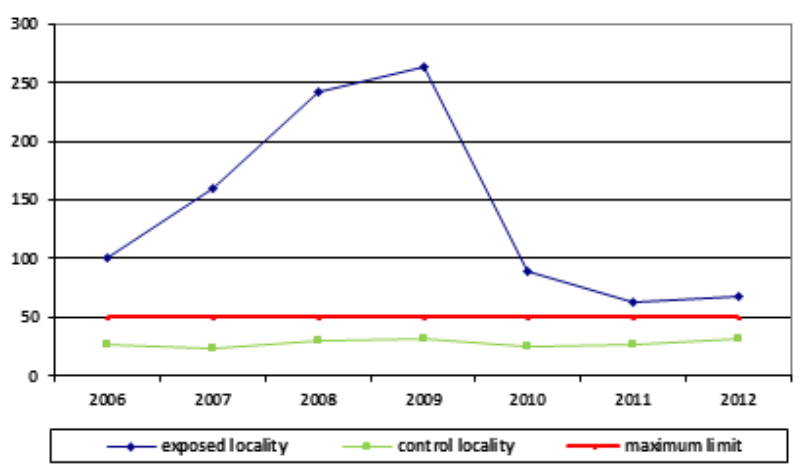

Figure 1 - The mean values of nitrates in water

For the second village (Limanu - control area) we collected 46 water samples from centralized system. The chemical analysis of water revealed that all samples are in the established sanitary rules for nitrate content (maximum 50mg/1).

Studying the prevalence of ischemic cardiopathy in both villages (Figure 2) we found that the control village has not major changes over the 6 years of study, ranging from $1.19 \%$ in 2006 to 1.62 $\%$ in 2010, maintained at the same level in 2011.

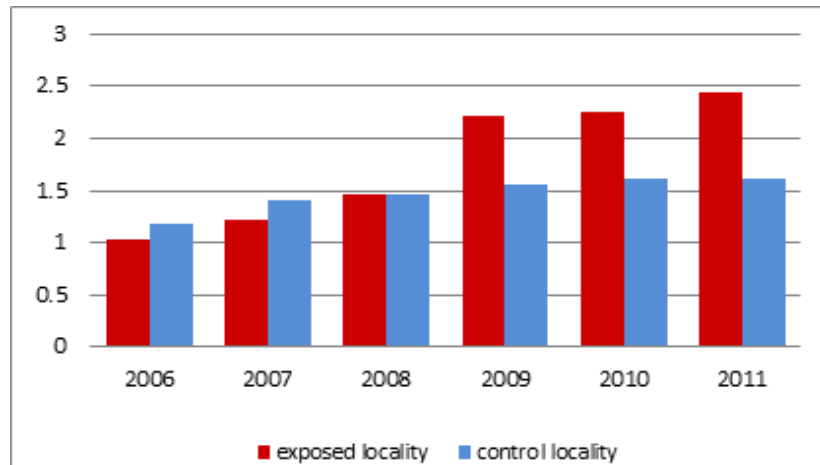

Figure 2 - Prevalence of ischemic cardiopathy

In village exposed to nitrates the values of prevalence are in a continuous increase from $1.04 \%$ in 2006 to $2.44 \%$ in 2011.

Following prevalence of type 2 diabetes, we noticed over the analyzed period that in the control village is an upward trend, between 2007 and 2010. While in 2006 and 2007 the prevalence of diabetes has the same value, it grows with less than $4 \%$ until 2011. In 2011 are no longer registered new cases of 
diabetes (Figure 3).

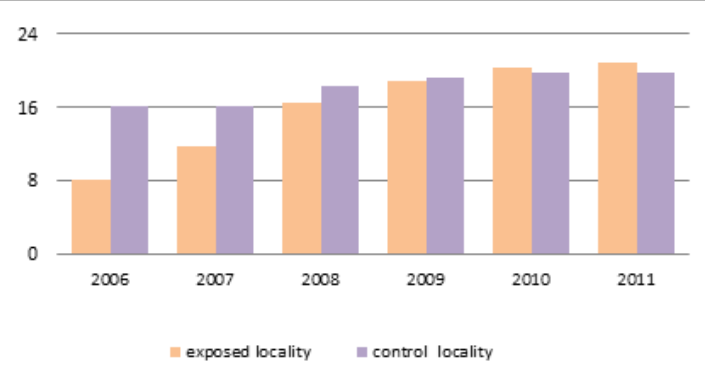

Figure 3 - Prevalence of diabetes type 2

For locality exposed to nitrate trend of growth continues each year. In this situation prevalence increases in 2011 with $12.74 \%$ compared to 2006 . Thus, we can say that in exposed locality diabetes recorded a growth of prevalence higher than in the control village in the same period.

Analyzing the cases of cancers, we found that in the locality exposed to high levels of nitrate in water the prevalence increases almost every year getting to be higher in 2010 than in 2006 with 2.8\%o.

For control locality variations in the prevalence of cancers are less than 1\%o between 2006 and 2010 (Figure 4).

Because of death in 2011 there is a decrease in the prevalence of cancers in both villages.

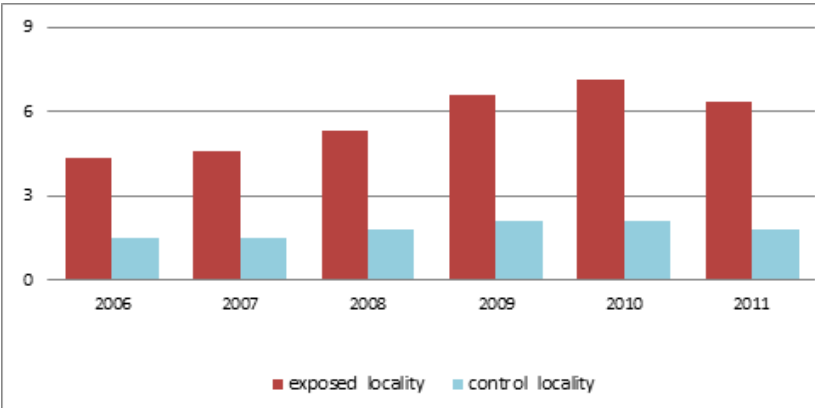

Figure 4 - Prevalence of cancers
Discussions

The trend of prevalence for ischemic cardiopathy may suggest that a reduced ability of blood to carry oxygen through the formation of methemoglobin together with other factors contribute to the occurrence of myocardial ischemia.

We have not found studies that establish a relationship between exposure to nitrates in environmental factors and prevalence of coronary heart disease.

No data was found in the literature about the prevalence of diabetes in areas exposed to nitrates, however according to studies on the pathogenesis of diabetes, oxidative stress is involved in the occurrence and development of diabetes cases and methemoglobin measurement is an important marker of stress oxidation in these patients [1,2].

A study published in 2008 by specialists from the National Research Center in Cairo demonstrates that in patients with non-insulin-dependent diabetes methemoglobin concentration is three times higher than in healthy subjects [1].

In these circumstances it is clear that the health of persons in general and patients with diabetes in particular, will be profoundly affected by exposure to elevated levels of nitrate, which is a risk factor for oxidation of iron ferrous $(\mathrm{Fe} 2+)$ in the structure of hemoglobin and the formation of methemoglobin.

As can be observed in Figure 4 the prevalence of cancers recorded higher values in locality exposed to nitrates than in the control locality.

The mechanism by which tumor cells are generated is based on the formation of nitrosamines, compounds which are generated by unification of nitrites with secondary amines, resulting from the cleavage of proteins. The formation of nitrosamines occurs predominantly at stomach due to acid environment that favors chemical reactions.

The specialists have different opinions about the role of nitrogen compounds from water in occurrence of cancer, and most studies are related to gastric cancer. The involvement of nitrates in the pathogenesis of gastric and colorectal cancer is 
supported by results of studies performed in America, Spain, China, Slovakia [3-7].

On the other hand, the specialists from Canada say that there is no causal relationship between gastric cancer and nitrates in water [8]. Moreover, American Environmental Agency is taking steps to include nitrates in the category of potential free carcinogenic substances.

\section{Conclusions}

Analyzing the water quality in the test locality, we found that two thirds of total samples have exceeded the maximum limit for nitrates.

The analysis of water in the unexposed locality found that chemical parameter monitored is within the sanitary norms.

Studying the evolution of chronic diseases we found a significant increase in the number of cases in exposed locality. We found a more pronounced increase of prevalence in 2006-2009, when the concentration of nitrates in water supplied through centralized system was on growing.

Finally, we can say that by chronic exposure to nitrates from water, certainly in association with other etiological factors, the risk of developing ischemic cardiopathy, diabetes and cancers increases, such is demonstrated by morbidity previously presented.

\section{References}

1. Moussa S.A. (2008). Oxidative Stress in Diabetes Mellitus. Romanian Journal of Biophysics. 18 (3), 225-236

2. Bandeira S. \& Guedes G. et al. (2012). Characterization of Blood Oxidative Stress in Type 2 Diabetes Mellitus Pactients: Increase in
Lipid Peroxidation and SOD Activity. Oxidative Medicine and Cellular Longevity. Volume 2012: 1-13. DOI: $10.1155 / 2012 / 819310$

3. Ward M., Dekok T., Levallois P., Brender J., Gulis G., Nolan B. \& Vanderslice J. (2005). Workgroup report: drinking-water nitrate and health-recent findings and research needs. Environmental Health Perspectives. 113 (11), 1607-1614. DOI: 10.1289/ehp. 8043

4. Morales-Suárez-Varela M.M., Llopis-Gonzalez A. \& Tejerizo-Perez M.L. (1995). Impact of nitrates in drinking water on cancer mortality in Valencia, Spain. European Journal of Epidemiology. 11(1), 15-21. DOI: 10.1007/ BF01719941

5. Chen K., Yu W., Ma X., Yao K. \& Jiang Q. (2005). The association between drinking water source and colorectal cancer incidence in Jiashan County of China: a prospective cohort study. The European Journal of Public Health. 15(6), 652656. DOI: $10.1093 /$ eurpub/cki027

6. Weyer PJ., Cerhan JR. \& Kross BC. (2001). Municipal drinking water nitrate level and cancer risk in older women: the Iowa Women's Health Study. Epidemiology. 12 (3), 327-338

7. Gulis G., Czompolyova M. \& Cerhan J.R. (2002). An ecologic study of nitrate in municipal drinking water and cancer incidence in Trnava District, Slovakia. Environmental Research. 88(3), 182-187. DOI: $10.1006 /$ enrs.2002.4331

8. Van Leeuwen J.A., Waltner-Toews D., Abernathy T., Smit B. \& Shoukri M. (1999). Associations between stomach cancer incidence and drinking water contamination with atrazine and nitrate in Ontario (Canada) agroecosystems, 1987-1991. International Journal of Epidemiology. 28(5), 836-840. DOI: $10.1093 / \mathrm{ije} / 28.5 .836$ 